\title{
Heart transplantation: the Berlin experience and perspectives
}

\author{
Mariano Francisco del Maria Javier ${ }^{1}$, Eva Maria Javier Delmo ${ }^{2}$, Roland Hetzer ${ }^{1}$ \\ ${ }^{1}$ Cardio Centrum Berlin, Berlin, Germany; ${ }^{2}$ Charité Research Organization, Charité-Universitätsmedizin Berlin, Berlin, Germany \\ Contributions: (I) Conception and design: All authors; (II) Administrative support: R Hetzer; (III) Provision of study materials or patients: EM Javier \\ Delmo, R Hetzer; (IV) Collection and assembly of data: All authors; (V) Data analysis and interpretation: All authors; (VI) Manuscript writing: All \\ authors; (VII) Final approval of manuscript: All authors. \\ Correspondence to: Mariano Francisco del Maria Javier. Cardio Centrum Berlin, Unter den Linden 21, 10117 Berlin, Germany. \\ Email: mfdmjavier@yahoo.de.
}

\begin{abstract}
In patients with end-stage heart failure, heart transplants are now an ingrained practice, as they provide satisfying long-term results with good predictability and quality of life. The successful outcome has evolved from the development of effective immunosuppression, recognition of allograft rejection through diagnostic modalities and improvement in donor organ perfusion. Unfortunately, transplant availability is constrained by the shortage of donor organs and is therefore considered a casuistic therapy. The outcome is defined by unwanted effects of immunosuppressants, increased tumor occurrence and chronic transplant angiopathies. In the long term, patients fear primarily the occurrence of renal insufficiency and secondly osteoporosis with its skeletal complications and corresponding pain. Nevertheless, the overall quality of life is not very limited; on the contrary, patients demonstrate a surprisingly meaningful lives 10-20 years after the transplant. Their physical presentation is similar to those with varying co-morbidities. Most of the 20-year surviving patients are physically active and happy with their daily lives. Medical ambition has seen heart transplantation become reality and develop into an influential force regarding heart surgery, immunology, pharmacology, organ logistics and medical ethics. Its development has also molded our definitions of death and has driven public and health care approval of medical advances. It has provided a strong solidarity among politicians, sociologists, physicians and citizens. Problems regarding ethics continue to endure, and will forecast heart transplants as a defining, but temporary era in human medicine. The donor organ shortage has stimulated the use of resuscitated donor hearts and encouraged exploration and advancement of mechanical circulatory support systems and xenotransplantation as alternatives in the management of end-stage heart failure.
\end{abstract}

Keywords: Congenital heart diseases; heart failure; heart transplantation; vasculopathy xenotransplantation

Submitted Feb 25, 2020. Accepted for publication Apr 21, 2020.

doi: $10.21037 / \mathrm{cdt}-20-290$

View this article at: http://dx.doi.org/10.21037/cdt-20-290

\section{Introduction}

The advent of heart transplantation has significantly influenced the modalities in advanced heart failure treatment and is now considered the therapy of choice for suitable patients. Since Barnard's first heart transplantation (1) on the 3rd of December 1967, heart transplantation has been significantly advanced through findings and insights of Shumway group at Stanford University during the 70s (2). They established a quality standard that enabled the implementation of heart transplantation in hospitals around the globe. In Germany, the first two heart transplantations were performed in Munich, which was resumed by Munich hospitals in the 80s, followed by our group in Hannover in 1983.

After completing 72 heart transplants in the time frame of 2 years (3) and with survival rates exceeding 20 years, our group relocated to Berlin in April 1986, where we launched an energetic transplantation program. Within 28 years of relocation, we completed 1,804 heart transplants, of which 189 were in children, 52 as re-transplants and 101 conjoined 


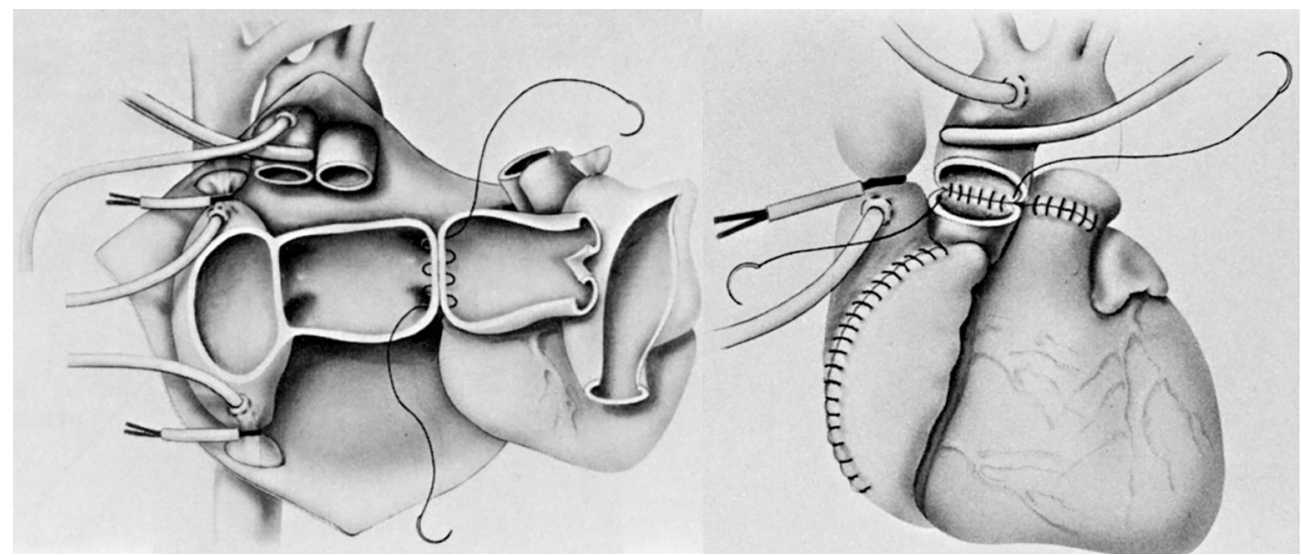

Figure 1 Technique of orthotopic heart transplantation.

heart and lung transplants.

This report briefly describe our experience in heart transplantation medicine with regards to the procurement and preservation of donor organs, surgical technique of heart transplantation, graft rejection monitoring, immunosuppression and its graft-associated diseases and sequelae as well as long term outcomes in terms of growth of transplanted hearts, psychosocial development of transplanted patients as well as survival. Likewise, this report summarizes pertinent issues, i.e., extended donor criteria using resuscitated hearts, transplantation for congenital heart diseases and use of ventricular assist devices as bridge to transplantation and ethical dilemma. Moreover, an outlook to resolve the current donor organ shortage is described.

\section{Transplantation medicine}

\section{Donor organ perfusion}

Donor organs are explanted after multiple successive brain death confirmations, flushed with protective solutions, cooled with ice and brought to the recipient, whereby ischemic times are tightly regulated to under $4-5$ hours. In the mid-2000s, we began using mechanical ex vivo perfusion using the Organ Care System (OCS) (see section on OCS) which preserves the beating heart in a $34{ }^{\circ} \mathrm{C}$ perfused oxygenated status from procurement to transport until transplantation. This facilitated a longer extracorporeal time (minimum 8 hours) which is highly applicable not only when organ procurement takes place in a distant location but also by minimizing the damage caused by cold ischemic preservation.

\section{Techniques of heart transplantation}

Most cardiac transplantations are implemented orthotopically (Figure 1), a technique greatly standardized in such procedures. The bi-caval anastomosis technique has largely replaced the bi-atrial approach due to lesser tricuspid insufficiency (4). However, tricuspid insufficiency has shown to be eliminated if the bi-atrial approach is executed as exhibited and suggested by the Stanford Group in the 1970s. Despite good long-term survival, execution of a cardiac transplant heterotopically has largely been deserted due to less encouraging outcomes.

\section{Monitoring of graft rejection}

Transplanted organs are at risk of suffering graft rejection via cellular or humoral (antibody-mediated) mechanisms. The early diagnosis of graft rejection, even before becoming clinically evident, is playing an increasingly important role. This has already been addressed back in the 70s, where the Stanford group developed the percutaneous transvenous endomyocardial biopsy, which for a while was considered gold-standard in early diagnostics of graft rejection. Nowadays, myocardial biopsy is indicated when rejection is clinically or echocardiographically suspected, in order to assess its character and severity. Since 1986 we use a noninvasive intramyocardial electrocardiogram for monitoring rejection $(5,6)$. In this technique, we implant a telemetric pacemaker with electrodes on the right and left ventricles during the transplantation, enabling us to monitor the ECG every night. It was documented that a decrease in the QRS amplitude by $10 \%$ relative to previously measured values is highly sensitive to a graft rejection process (Figure 2). 
Intramyocardial electrocardiogram

(IMEG) monitoring of graft rejection

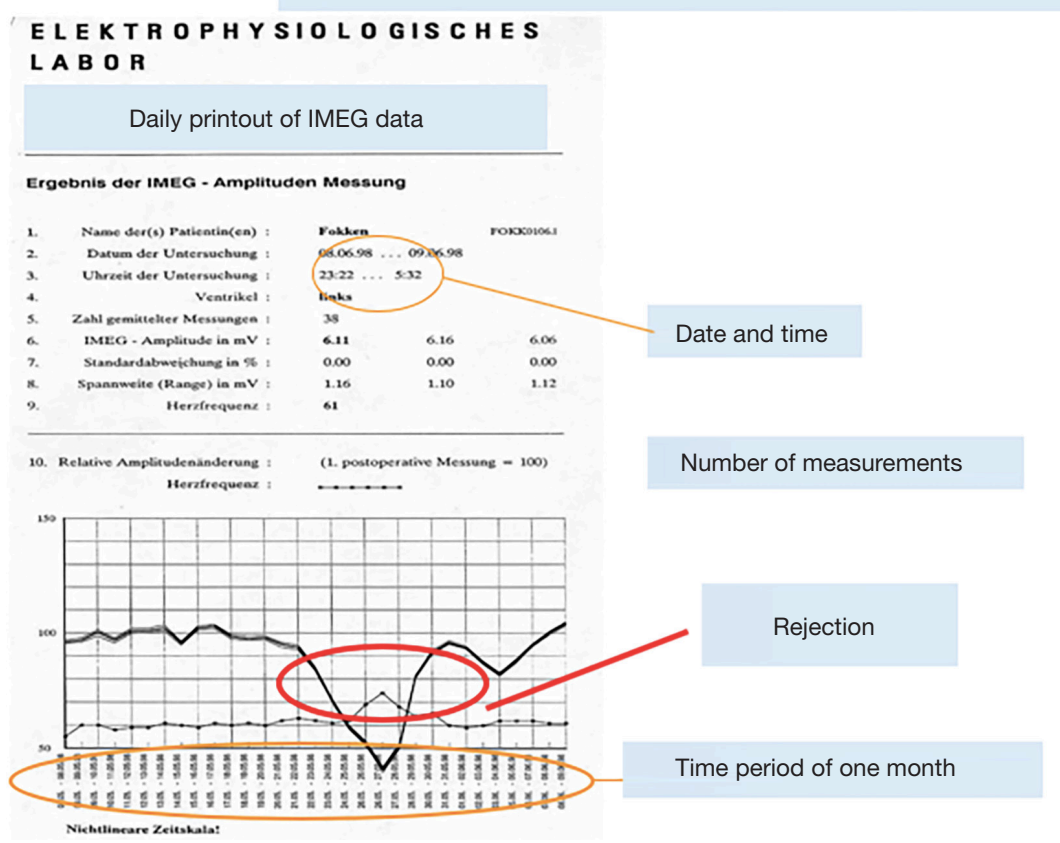

Figure 2 Monitoring of graft rejection.

The evolution of the QRS amplitude also enables documentation of the course of rejection. This monitoring system likewise allows observation of patients that are not in our proximity - for instance the monitoring of a patient from Japan that was transplanted in our center and who returned home for continued medical care.

Echocardiography in the form of tissue duplex or strain and strain rate measurements are also important non-invasive methods in the diagnosis of graft rejection, however, it requires a certain level of expertise of the examining physician and is bound to the transplant clinic.

It can be said that an acute graft rejection can be diagnosed with certainty, provided the aforementioned diagnostic modalities are implemented consistently.

\section{Immunosuppression}

Immunosuppression of transplanted patients has had a long and tortuous history. An important turning point was the introduction of cyclosporin-A, which was used for the first time at the Stanford University in 1980 for heart transplants (7).

The initial form was a high-dose monotherapy with cyclosporine, which however was associated with significant organ toxicity. The group of Cabrol in Paris introduced a four-fold therapy with antithymocyte-globulin and steroids for induction and delayed cyclosporin-A therapy (8). We have practiced an induction therapy with antithymocyteglobulin and a moderate continuous-threefold-therapy with cyclosporin-A, Azathioprine or rather modern antiproliferative mycophenolate mofetil and everolimus, and steroids (3).

When acute graft rejection was suspected or confirmed, we intensified the immunosuppression, initially by giving methylprednisolone boluses or, in the case of rejection persistence or hemodynamic deterioration, antithymocyte-globulin and, if necessary, plasmapheresis and immunoadsorption.

\section{Outcome}

Late graft-associated diseases and sequelae of immunosuppression therapy

Transplant vasculopathy

Development of cardiac allograft vasculopathy (CAV) has 
become a contributor of mortality in the long-term followup of transplant patients and is the most frequent cause for necessity of re-transplantation. CAV is characterized by a proliferation of vascular smooth muscle cells, that begins in all vessel parts, develops differently in different regions, may be masked by classic arteriopathies and may lead to acute or chronic ischemia of the transplanted organ. However, despite multiple immunologic and non-immunologic risk factors having been identified in its pathogenesis, its management remains insufficient, albeit the use of statins and certain immunosuppression protocols providing promising options. Although stenotic changes of epicardial coronary arteries are manageable with interventional or surgical revascularization in non-transplant patients, they do not prove a prognostic advantage (8). This is due to the additional frequent presence of distal microvascular arteriopathies, which contribute to the occurrence of fatal cardiac events and thus have a deleterious effect on prognosis (9). The latter impedes on diagnoses made by coronary angiography, which remain the gold standard in the diagnosis of $\mathrm{CAV}$ due to their ubiquitous availability.

\section{Tumor development}

A persisting challenge for patients who underwent heart transplantation is the development of neoplastic diseases, foremost lymphomas and various iterations of posttransplant lymphoproliferative diseases (PTLD). The latter seems to arise as the consequence of continued improvement of long-term immunosuppressants. A major factor presumed to drive neoplastic transformation may also be due to the Epstein Barr virus (EBV), as such cancers are frequently seen to contain the EBV genome. The EBVseronegativity at transplantation suggests a higher potential risk in children for the development of PTLD than in adult patients (10). Furthermore, it has been postulated that an induction therapy may enhance the possibility of developing cytomegalovirus (CMV) disease and PTLD (11). However, no causality could be demonstrated between induction therapy and the incidence of CMV disease.

\section{Other comorbidities}

After transplantation, de novo pathologies may arise, or an exacerbation of antecedent comorbidities may occur. Within 1 year after transplant, $75 \%$ have become hypertensive, a figure that rises to $95 \%$ within 5 years post-transplant. Thirty-five percent suffer renal insufficiency within 5 years post-transplant, with $10 \%$ having a creatinine level of $>2.5 \mathrm{mg} / \mathrm{dL}, 2-3 \%$ requiring long-renal replacement therapy and a few necessitating a kidney transplant. The development of insufficient kidney function post-transplant is grounded on the use of cyclosporin-A, the presence of hypertension and atherosclerosis, ultimately requiring specialized nephrological treatment (12).

Important side effects of the transplant and the immunosuppressive treatment are the development of hypertension, $75 \%$ of the patients develop this during the first year after the transplant and after 5 years, it is detectable in $95 \%$. Similarly, $35 \%$ of patients develop renal insufficiency within 5 years, and later on the number of those who eventually need to be dialyzed and who may also need a kidney transplant increases steadily. Late renal failure is primarily associated with chronic cyclosporin-A intake. It is lower in other forms of immunosuppression.

Hyperlipidemia, and especially hypercholesterolemia, is noticeable in most of the patients and a significant proportion of patients also develop diabetes mellitus 2-5 years after transplant. The constant connection of the patients to a specialized center is therefore of great importance for monitoring and determines to a high degree the chance for the patients to experience a good long-term result.

\section{Cardiac transplant growth}

Data regarding growth and development of cardiac transplants in very young patients is insufficient and only few address cardiac remodeling after transplant. Studies on our patients have shown, that despite the use of steroids and intensive immunosuppressive regimens, growth has been normal (13). The transplanted organs showed normal growth, despite the initial discrepancy between donor and recipient weight and total body surface area (14) (Figure 3). Relatively large or small donor organs were able to adapt to the necessities of the recipients' circulations within months of implantation and reached weight and surface area adequate sizes.

\section{Psychosocial development of a heart transplant patient}

Psychological evaluations of 182 patients in respect to the mental ramifications of cardiac transplants have demonstrated a significant effect of chronic immunosuppressive therapy in combination with social insecurity, with regards to the development of depression. Overall, transplantation recipients do not fail to thrive in psycho-social aspects, with scores similar to the wider public (15). However, some suffer impairment, both in their 
A

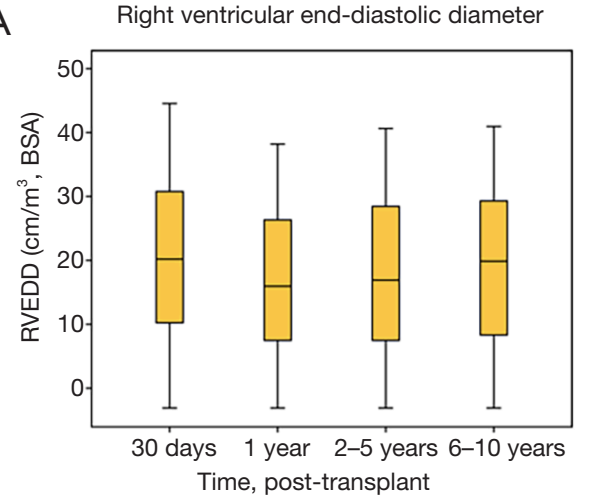

C

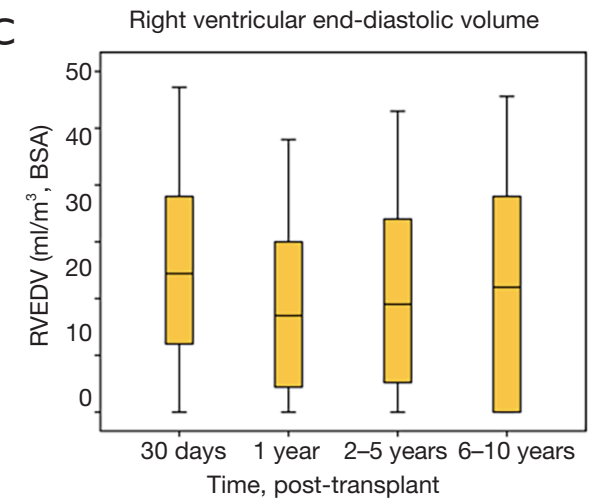

$\mathrm{E}$

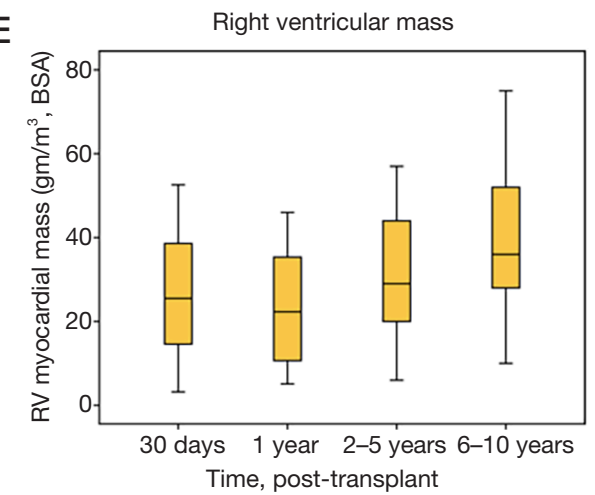

B

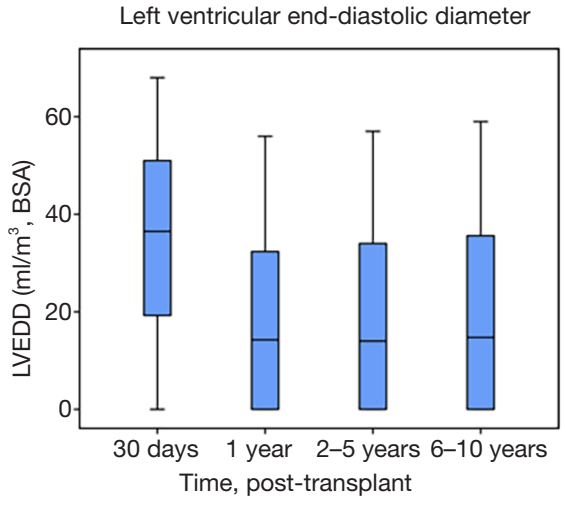

D

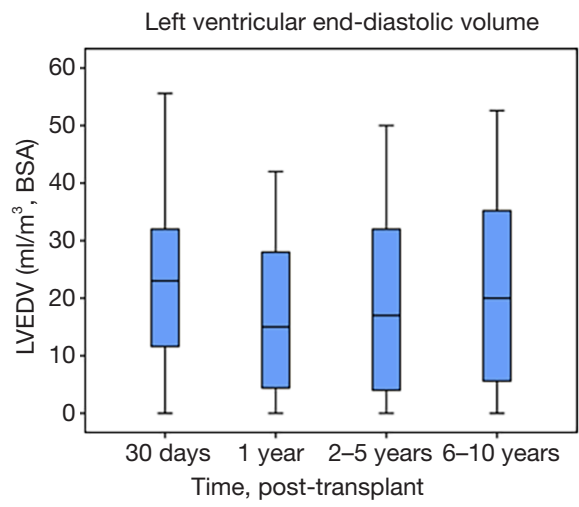

$\mathrm{F}$

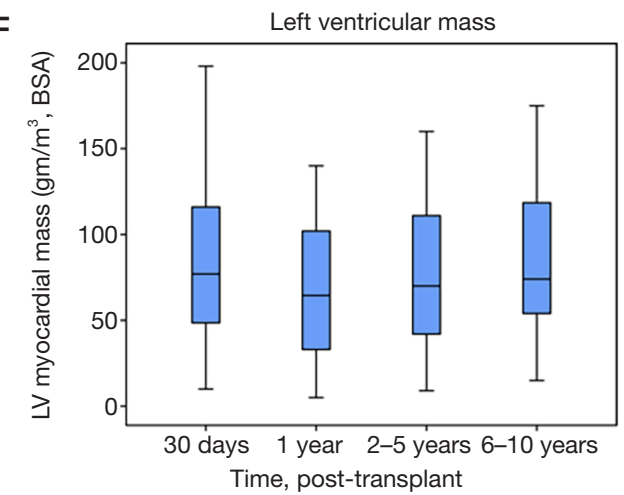

Figure 3 Cardiac dimensions and volumes measured over time after transplantation. (A) RVEDD; (B) LVEDD; (C) RVEDV; (D) LVEDV; (E) RV myocardial mass; (F) LV myocardial mass. RVEDD, right ventricular end-diastolic diameter; LVEDD, left ventricular end-diastolic diameter; RVEDV, right ventricular end-diastolic volume; LVEDV, left ventricular end-diastolic volume; RV, right ventricular; LV, left ventricular. 
re-adjustment to their professional routine and in their functional activity, in comparison to their colleagues.

\section{Survival}

In accordance to the ISHLT Report of 2019, the survival of transplanted patients encompassed by the Stanford Group in the 1980s reached a figure similar to the present (16). Survival rates of our transplanted patients over the past 25 years were $78 \%, 62 \%, 48 \%, 36 \%$ and $22 \%$ after $1,5,10,15$ and 20 years, respectively. This encompasses all patients including those that have been transplanted after bridging with an assist device or a total artificial heart. The results have deteriorated especially during the last years due to the fact that patients are only transplanted if they are categorized as "high-urgent", are intensive-care patients or are catecholamine dependent, or are suffering from an acutely life-threatening complication on an assist device, the latter representing the majority. Such complications encompass infections of the assist device or embolic events such as a stroke. Donor organ paucity has also led to the use of organs from increasingly older donors that do not possess optimal organ function.

\section{Donor organ shortage}

Lack of donor organ is regarded as the emergent issue in transplantation medicine. Its scarcity resulted to a decrease in number of transplantations and an enhanced prolongation of recipient waiting times correspondent to increase in mortality and progressive organ deterioration while on the transplant waiting list.

\section{Extended donor criteria}

Albeit transplant medicine centered on young donors ( $<35$ years old), most demographic restrictions have been modified, and organs from up to 70-year-old donors are now transplanted, as long as there are no pathologies or anomalies. In Europe, it is now common to transplant hearts from donors up to 65 years old, with ventricular hypertrophy or with a history of extended cardiac arrest. Despite utilizing these marginal donors, donor organ scarcity persists.

\section{The use of resuscitated donor hearts in heart transplantation}

Expansion of organ donor criteria is an essential strategy to implement the limited organ availability. In light of the scarcity of donor organs, the use of hearts from patients who expired from cardiopulmonary arrest has been considered [Donation after Circulatory Death (DCD)] to bridge the gap. This idea was supported by the observation that donor hearts retains viability and functionality after successful donor resuscitation, provided that the donor normal cardiac function is restored. Data from several retrospective review support the notion that if standard donor and recipient transplantation criteria are met, a history of donor cardiac arrest should not preclude an organ for consideration for clinical transplantation. A major factor is the duration of circulatory arrest. Ali et al. (17) described the successful transplantation of a heart retrieved from a donor who suffered circulatory arrest for 23 minutes. Several groups in Belgium, Australia, UK and the US have developed concepts to sustain viability of donor organs before explantation with the help of perfusion systems (18-20). The criteria for brain death naturally play a major role in this regard. Rajab and Singh (21) suggested OCS-assisted perfusion of an organ obtained from a DCD donor, in order to assess possible (long-term) restoration of cardiac function and hence decide on transplant viability of that organ. Future studies and improvements in regard to this topic are still to be expected.

\section{OCS}

The expanding deficit between allocation and necessity for allografts in conjunction with altering the specifics of both donors and recipients have preceded to the revival of enthusiasm over mechanical perfusion to enhance the quality and quantity of donor hearts for transplantation.

New perspectives have been created in transplant medicine and its patients through the mechanical perfusion of donor organs. So far, organs were disconnected from their circulation and flushed with a cardioprotective solution, transported in containers cooled to $4{ }^{\circ} \mathrm{C}$ and transported to the transplant center within a few hours to ensure implantation as swiftly as possible. A constant mechanical perfusion with a blood-like solution at body temperature may prolong conservation times and minimize organ damage. In addition, donor organs that used to be declared unusable, could now be revitalized.

The OCS is used to resuscitate and effectively implant donor hearts from patients that have suffered a cardiopulmonary death and is available in countries such as the United Kingdom, Australia, Belgium and Austria 
$(22,23)$. This system is also used for organs retrieved from donors who have suffered from an irreversible brain death.

Prolonged conservation times enable transportation of lungs and hearts from distant European countries to Germany.

The donor heart is immediately connected to the OCS system after explantation and kept in a contractility state until its disconnection for implantation. The system sustains cardiac viability through continuous perfusion with oxygen-rich blood, which is enhanced by TransMedics solutions designed to minimize inflammatory reactions and sustain the cardiac tissue during transport. At least 1,100 $\mathrm{mL}$ of the donor's blood is required for the system filtered by a TransMedics blood collection set and, together with the TransMedics solutions, is used to continually perfuse the donor organ. Monitoring and control of hemodynamic and metabolic parameters are vital during transport. Heart transplantation and subsequent standard patient care is performed (24).

Transplant surgeons regard mechanical perfusion systems a means to improve transplant medicine and increase the number of donor organs. Although this system is used in Germany for heart- and lung-transplantation, it is not financed or covered by medical insurance companies (25).

\section{Special issues}

\section{Transplantation for congenital heart diseases}

The transplantation for complex congenital heart defects and heart failure requires an individually adapted surgical procedure $(26,27)$. However, it is not merely the technical modification in accordance with the original error or the corrective surgery already carried out before the transplant (28) but also the consideration of the chronic changes in the systemic and pulmonary tract, which have sometimes occurred over many years. Patients with a situs inversus can also be transplanted with certain technical variations $(29,30)$.

We had patients ( $\mathrm{n}=17,1.6-17$ years of age) suffering from transposition of the great arteries and who have undergone an atrial switch operation or a complete correction of the transposition can be managed with intraoperative modifications of the atria and atrial septum. It is also possible to successfully transplant patients postFontan-operation ( $\mathrm{n}=10 ; 5$ children, 2-16 years old; 5 adults, 21-58 years old). In these cases, timing of the transplantation is vital, as chronic changes of the systemic venous circulation may have been established and are thus prone to higher risk of failure. However, there is a future in the use of mechanical circulatory support systems for early circulatory improvement (29).

\section{Use of mechanical circulatory assist devices as a bridge to transplantation}

Successful implementation of circulatory support with the aim in bridging time towards transplantation was performed by us in Berlin, Germany in1987 in an adult and in 1990 in a child $(31,32)$. The 8 -year-old boy was supported by a pulsatile-flow, paracorporeal left ventricular assist device (LVAD) of adult size (32). This case led to the development of ventricular assist devices for all ages, from infants to adults in collaboration with the Berlin Heart company. Up to date, these systems are the only support systems available for and neonates and children (under 15-20 kg body mass) $(33,34)$. Additionally, many new devices have been developed based on centrifugal mechanisms, in which blood flow is not created in a pulsatile manner, but is rather propelled continuously by a turbine $(35,36)$.

These types of systems are quiet, require less energy and have now been in practice for $8-9$ years. The bridgeto-transplant concept is still implemented today, having paved the path towards developing permanent, implantable mechanical circulatory support devices that, in light of donor organ scarcity, are of vital importance in heart transplantation and that may be considered in patients that do not qualify for transplant, such as those over 65 years of age. Especially in this age group, the number of heart failure patients increase drastically, making the increased use of such assist devices in these types of patients an expected foresight.

\section{Ethical dilemma}

Heart transplantation, a procedure with which a terminal patient may regain normal physical capacities within a short period of time, is a humbling and fascinating experience. This, however, does not entail a longer life expectancy, being on average 10-12 years. Pathologies of the transplanted organ itself, such as CAV, lead to limited life expectancy, which is currently at most 30-35 years. During this time, many patients may require re-transplantation to remain alive. Donor organ paucity warrants the criticism on the concept of re-transplantation, which must be weighed in its importance compared to patients that await and require their first transplantation. 
Over time, the risk of developing graft vasculopathy increases, sometimes necessitating a re-transplant to avoid mortality. Re-transplant outcomes are certainly poorer than the outcomes of primary transplants, whilst additionally entailing critical ethical problems. A potential ethical resolution may involve the implementation of mechanical circulatory support devices, which are conveniently exchangeable in the event of device malfunction. Rapidly technological advances in regard to these pumps may eventuate their implementation for long-term support, as is the present case in the older population and in fewer instances in children.

\section{Perspectives}

Despite the extensive efforts to increase availability of allografts, i.e., transplanting resuscitated donor hearts and extracorporeal mechanical donor heart perfusion, the scarcity of donor organ prevails, hence the search for alternative to allografts have begun.

\section{Xenotransplantation}

Improvements are being seen in the results of organ and cell allotransplants. The paucity of donor organs however remains the largest problem of transplant medicine (37). Xenotransplants between pigs and humans could lead to an unlimited supply of organs and bridge the gap of organ deficit (38).

Xenotransplantation is not a novel concept, having been performed in multiple clinical trials in the past 300 years (39). Examples include the clinical xenotransfusion of blood performed by Jean Baptiste Denis in the $17^{\text {th }}$ Century, porcine corneal xenotransplantation in the early $19^{\text {th }}$ century and the xenotransplantation of non-human primates (NHPs) by Reemtsma in the 1960s (39,40) and many more (41). A general overview of the field of xenotransplant models for NHP from pigs (until 1997) was published by Lambrigts et al. (42) and its progress from 1997-2013 published in 2014 (43).

In recent years, results are improving in the use of genetically altered pigs as organ donors, sparking hopes to initiate such trials in clinical studies (44-46). New studies are describing the preemptive selection of patients to undergo the first clinical studies for xenotransplantation of organs and of pancreatic islet cells (47).

\section{Cardiac xenotransplantation}

Mohiuddin et al. (48) have shown long-term survival of
NHPs who received genetically modified, heterotopic heart transplants from pigs. As a result of porcine genetic modifications (GTKO.hCD37.hThrombomodulin) in combination with a successful management plan based on the use of chimeric monoclonal anti-CD30-antibodies $(\mathrm{mAb})$, humoral rejection and dysregulation of the coagulation cascade could be prevented and the survival of the xenotransplanted organ was ensured for over 900 days.

Iwase et al. (49) were able to successfully demonstrate the prevention of $\mathrm{T}$-cell activation with the combined use of anti-CD30 $\mathrm{mAB}$ and belatacept in heterotopic xenotransplantation models from pigs to baboons.

\section{Ethical and regulatory aspects}

Important considerations in the approach to clinical studies surround xenotransplantation are ethical questions (50), the acceptance of xenotransplantation by hospital staff (51) and the general population with varying cultural and religious backgrounds (52-54). Schuurman has recently discussed the regulatory aspects of xenotransplantation in Europe and the United States in multiple publications $(55,56)$.

\section{The future of xenotransplantation}

With the experience gained $(38,57)$ and new developments $(48,58,59)$ in xenotransplants, the first application of pancreatic islet cells as xenotransplants can be reached (46). The research community must decide upon: (I) whether successful orthotopic heart transplantations in pig to NHP models must precede clinical trials (60) and (II), whether preclinical thresholds can be loosened with regards to kidney xenotransplants (61).

The renaissance of xenotransplantation is apparent $(45,62)$, where survival of xenotransplanted cells and organs have been prolonged with the use of costimulation blockers $(63,64)$. It is foreseeable that our increasing knowledge on the porcine genome (65) will lead to further genetic manipulations in the future. It can be said that the clinical application of cardiac xenotransplantation is more in our reach than ever.

\section{Acknowledgments}

Funding: None.

\section{Footnote}

Provenance and Peer Review: This article was commissioned 
by the editorial office, Cardiovascular Diagnosis and Therapy for the series "Heart Failure in the Young and Old: Insights into Various Therapies". The article has undergone external peer review.

Conflicts of Interest: All authors have completed the ICMJE uniform disclosure forms (available at http://dx.doi. org/10.21037/cdt-20-290). The series "Heart Failure in the Young and Old: Insights into Various Therapies" was commissioned by the editorial office without any funding or sponsorship. RH served as the unpaid Guest Editor of the series and serves as an unpaid editorial board member of Cardiovascular Diagnosis and Therapy from July 2019 to Jun 2021. The authors have no other conflicts of interest to declare.

Ethical Statement: The authors are accountable for all aspects of the work in ensuring that questions related to the accuracy or integrity of any part of the work are appropriately investigated and resolved.

Open Access Statement: This is an Open Access article distributed in accordance with the Creative Commons Attribution-NonCommercial-NoDerivs 4.0 International License (CC BY-NC-ND 4.0), which permits the noncommercial replication and distribution of the article with the strict proviso that no changes or edits are made and the original work is properly cited (including links to both the formal publication through the relevant DOI and the license). See: https://creativecommons.org/licenses/by-nc-nd/4.0/.

\section{References}

1. Barnard CN. The operation. A human cardiac transplant: an interim report of a successful operation performed at Groote Schuur Hospital, Cape Town. S Afr Med J 1967;41:1271-4.

2. Stinson EB, Griepp RB, Dong E Jr, et al. Results of human heart transplantation at Stanford University. Transplant Proc 1971;3:337-42.

3. Hetzer R, Warnecke H, Schüler S, et al. Heart transplantation--a two-year experience. Z Kardiol 1985;74 Suppl 6:51-8.

4. Dandel M, Hummel M, Loebe M, et al. Right atrial geometry and tricuspid regurgitation after orthotopic heart transplantation: benefits of a modified biatrial surgical technique. J Heart Lung Transplant 2001;20:246-7.

5. Hetzer R, Potapov E, Müller J, et al. Daily non-invasive rejection monitoring improves long-term survival in pediatric heart transplantation. Ann Thorac Surg 1998;66:1343-9.

6. Warnecke H, Schüler S, Goetze HJ, et al. Noninvasive monitoring of cardiac allograft rejection by intramyocardial electrogram recordings. Circulation 1986;74:III72-6.

7. Brumbaugh J, Baldwin JC, Stinson EB, et al. Quantitative analysis of immunosuppression in cyclosporine-treated heart transplant patients with lymphoma. J Heart Transplant 1985;4:307-11.

8. Gluckman JC, Rottembourg J, Mattei MF, et al. Immunologic surveillance of cardiac transplant recipients treated with rabbit antilymphocyte globulin. Presse Med 1983;12:2636

9. Hiemann NE, Wellnhofer E, Knosalla C, et al. Prognostic impact of microvasculopathy on survival after heart transplantation: evidence from 9713 endomyocardial biopsies. Circulation 2007;116:1274-82.

10. Zuppan CW, Wells LM, Kerstetter JC, et al. Cause of death in pediatric and ind infant heart transplant recipients: review of a 20 year, single-institution cohort. J Heart Lung Transplant 2009;28:579-84.

11. Schubert S, Abdul-Khaliq H, Lehmkuhl HB, et al. Diagnosis and treatment of post-transplantation lymphoproliferative disorder in pediatric heart transplant patients. Pediatric Transplantation 2009;13:54-62.

12. Simmonds J, Burch M, Dawkins H, et al. Heart transplantation after congenital heart surgery: improving results and future goals. Eur J Cardiothorac Surg 2008;34:313-7.

13. Delmo Walter EM, Huebler M, Stamm C, et al. Adaptive growth and remodeling of transplanted hearts in children. Eur J Cardiothorac Surg 2011;40:1374-82; discussion 1382-3.

14. Delmo Walter EM, Huebler M, Schubert S, et al. Influence of size disparity of transplanted hearts on cardiac growth in infants and children. J Thorac Cardiovasc Surg 2012;143:168-77.

15. Hetzer R, Albert W, Hummel M, et al. Status of patients presently living 9-13 years after orthotopic heart transplantation. Ann Thorac Surg 1997;64:1661-8.

16. Khush KK, Cherikh WS, Chambers DC, et al. The International Thoracic Organ Transplant Registry of the International Society for Heart and Lung Transplantation: Thirty-sixth adult heart transplantation report - 2019; focus theme: Donor and recipient size match. J Heart Lung Transplant 2019;38:1056-66.

17. Ali AA, Lim E, Thanikachalam M, et al. Cardiac arrest in 
the organ donor does not negatively influence recipient survival after heart transplantation. Eur J Cardiothorac Surg 2007;31:929-33.

18. Tchana-Sato V, Ledoux D, Detry O, et al. Successful clinical transplantation of hearts donated after circulatory death using normothermic regional perfusion. J Heart Lung Transplant 2019;38:593-8.

19. Messer S, Lannon J, Wong E, et al. The potential of transplanting hearts from donation after circulatory determined death (DCD) donors within the United Kingdom. J Heart Lung Transplant 2015;34:S275.

20. Trivedi JR, Gallo M, Slaughter MS. Use of resuscitated donor hearts for transplantation: same results either side of the Atlantic Ocean. J Thorac Cardiovasc Surg 2017;154:539.

21. Rajab TK, Singh SK. Donation after cardiac death heart transplantation in america is clinically necessary and ethically justified. Circ Heart Fail 2018;11:e004884.

22. Chew HC, Dhital K. Outcomes of donation after circulatory death heart transplantation in Australia. J Am Coll Cardiol 2019;73:1447-59.

23. Ardehali A, Esmailian F, Deng M, et al; Exvivo perfusion of donor hearts for human heart transplantation (PROCEED II): a prospective, openlabel, multicentre, randomised non-inferiority trial. Lancet 2015;385:2577-84.

24. NICE. OCS Heart system for heart transplant. 2016. Available online: https://www.nice.org.uk/advice/ mib86/resources/ocs-heart-system-for-heart-transplantpdf-63499411285189

25. Transplantation: Neue Perspektiven durch Organperfusion. 2019. Available online: https:// www.medica.de/de/News/Redaktionelle_News/ Transplantation_Neue_Perspektiven_durch_ Organperfusion

26. Chartrand C, Guerin R, Kangah M, et al. Pediatric heart transplantation: surgical considerations for congenital heart diseases. J Heart Transplant 1990;9:608-16; discussion 616-7.

27. Vouhé PR, Tamisier D, Le Bidois J, et al. Pediatric cardiac transplantation for congenital heart defects: surgical considerations and results. Ann Thorac Surg 1993;56:1239-47.

28. Montalvo J and Bailey LL. Operative methods used for heart transplantation in complex univentricular heart disease and variations in atrial situs. Operative Techniques in Thoracic and Cardiovascular Surgery 2010;15:172-84.

29. Hetzer R, Weng Y, Delmo Walter EM. State of the art in paediatric heart transplantation: the Berlin experience. Eur J Cardiothorac Surg 2013;43:258-67.

30. Kanter KR, Mahle WT, Vincent RN, et al. Heart transplantation in children with a Fontan procedure. Ann Thorac Surg 2011;91:823-9; discussion 829-30.

31. Hennig E. Design criteria for pediatric mechanical circulatory support systems (PMCSS). In: Ferrazzi P, Parenzan L. editors. Annals of the concerted $\backslash$ action HEART 1991-1992. Bergamo: Commission of the European Communities, 1991:30-43.

32. Warnecke H, Berdjis F, Hennig E, et al. Mechanical left ventricular support as a bridge to transplantation in childhood. Eur J Cardiothorac Surg 1991;5:330-3.

33. Hetzer R, Loebe M, Potapov EV, et al. Circulatory support with pneumatic paracorporeal ventricular assist device in infants and children. Ann Thorac Surg 1998;66:1498-506.

34. Hetzer R, Potapov EV, Stiller B, et al. Improvement in survival after mechanical circulatory support with pneumatic pulsatile ventricular assist devices in pediatric patients. Ann Thorac Surg 2006;82:917-24.

35. Hetzer R, Stiller B. Technology insight: use of ventricular assist devices in children. Nat Clin Pract Cardiovasc Med 2006;3:377-86.

36. Hetzer R, Alexi-Meskishvili V, Weng Y, et al. Mechanical cardiac support in the young with the Berlin Heart EXCOR pulsatile ventricular assist device: 15 years' experience. Semin Thorac Cardiovasc Surg Pediatr Card Surg Annu 2006;9:99-108.

37. Ekser B, Cooper DK, Tector AJ. The need for xenotransplantation as a source of organs and cells for clinical transplantation. Int J Surg 2015;23:199-204.

38. Ekser B, Ezzelarab M, Hara H, et al. Clinical xenotransplantation: the next medical revolution? Lancet 2012;379:672-83.

39. Cooper DKC, Ekser B, Tector AJ. A brief history of clinical xenotransplantation. Int J Surg 2015;23:205-10.

40. Hara H, Cooper DK. The immunology of corneal xenotransplantation: a review of the literature. Xenotransplantation 2010;17:338-49.

41. Cooper DKC. Early clinical xenotransplantation experiences-An interview with Thomas E. Starzl, MD, PhD. Xenotransplantation 2017. doi: 10.1111/xen.12306.

42. Lambrigts D, Sachs DH, Cooper DK. Discordant organ xenotransplantation in primates: world experience and current status. Transplantation 1998;66:547-61.

43. Cooper DKC, Satyananda V, Ekser B, et al. Progress in pig-to-non-human primate transplantation models (1998-2013): a comprehensive review of the literature. 
Xenotransplantation 2014;21:397-419.

44. Cooper DK, Ekser B, Ramsoondar J, et al. The role of genetically engineered pigs in xenotransplantation research. J Pathol 2016;238:288-99.

45. Perkel JM. Xenotransplantation makes a comeback. Nat Biotechnol 2016;34:3-4.

46. Schuurman HJ. Pig-to-nonhuman primate solid organ xenografting: recent achievements on the road to first-inman explorations. Xenotransplantation 2016;23:175-8.

47. Cooper DKC, Wijkstrom M, Hariharan S, et al. Selection of patients for initial clinical trials of solid organ xenotransplantation. Transplantation 2017;101:1551-8.

48. Mohiuddin MM, Singh AK, Corcoran PC, et al. Chimeric 2C10R4 anti-CD40 antibody therapy is critical for longterm survival of GTKO.hCD46.hTBM pig-to-primate cardiac xenograft. Nat Commun 2016;7:11138.

49. Iwase H, Ekser B, Satyananda V, et al. Pig-to-baboon heterotopic heart transplantation--exploratory preliminary experience with pigs transgenic for human thrombomodulin and comparison of three costimulation blockade-based regimens. Xenotransplantation 2015;22:211-20.

50. Olver IN. Ethical issues with xenotransplantation clinical trials. Med J Aust 2016;204:212.

51. Abalovich A, Matsumoto S, Wechsler CJ, et al. Level of acceptance of islet cell and kidney xenotransplants by personnel of hospitals with and without experience in clinical xenotransplantation. Xenotransplantation 2017. doi: 10.1111/xen.12315.

52. Mathieu R. Jewish ethics and xenotransplantation. Xenotransplantation 2016;23:258-68.

53. Ríos A, López-Navas AI, Martínez-Alarcón L, et al. Acceptance of organ xenotransplantation among Latin American immigrants resident in the United States. Xenotransplantation 2016;23:269-78.

54. Paris W, Jang K, Colsch L, et al. Psychosocial challenges of xenotransplantation: the need for a multidisciplinary,

Cite this article as: Javier MFDM, Javier Delmo EM, Hetzer R. Heart transplantation: the Berlin experience and perspectives. Cardiovasc Diagn Ther 2021;11(1):243-253. doi: 10.21037/cdt-20-290 religious, and cultural dialogue. Xenotransplantation 2016;23:335-7.

55. Schuurman HJ. Regulatory aspects of clinical xenotransplantation. Int J Surg 2015;23:312-21.

56. Schuurman HJ. Microbiological safety of clinical xenotransplantation products: monitoring strategies and regulatory aspects. A commentary. Xenotransplantation 2016;23:440-3.

57. Cooper DK, Ezzelarab MB, Hara H, et al. The pathobiology of pig-to-primate xenotransplantation: a historical review. Xenotransplantation 2016;23:83-105.

58. Kim S, Higginbotham L, Mathews D, et al. CD4 depletion is necessary and sufficient for long-term nonhuman primate xenotransplant survival. [abstract]. Am J Transplant 2017;17:479.

59. Butler JR, Tector AJ. CRISPR genome-editing: a medical revolution. J Thorac Cardiovasc Surg 2017;153:488-91.

60. Cooper DK. Is successful orthotopic heart transplantation in the pig-to-non-human primate model required before proceeding to a clinical trial? Xenotransplantation 2016;23:328-9.

61. Cowan PJ, Ierino FL. Reducing the threshold for clinical renal xenotransplantation. Transplantation 2017;101:692-3.

62. Samy KP, Butler JR, Li P, et al. The role of costimulation blockade in solid organ and islet xenotransplantation. J Immunol Res 2017;2017:8415205.

63. Buermann A, Römermann D, Baars W, et al. Inhibition of B-cell activation and antibody production by triggering inhibitory signals via the PD-1/PD-ligand pathway. Xenotransplantation 2016;23:347-56.

64. Cowan PJ, Tector AJ. The resurgence of xenotransplantation. Am J Transplant 2017;17:2531-6.

65. Marx H, Hahne H, Ulbrich SE, et al. Annotation of the domestic pig genome by quantitative proteogenomics. J Proteome Res 2017;16:2887-98. 